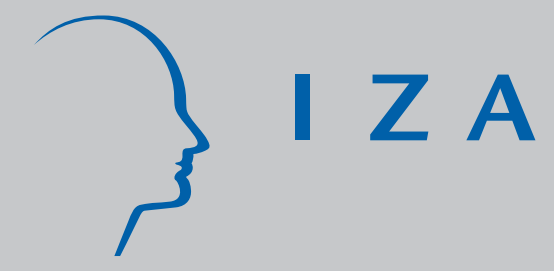

IZA DP No. 1546

Extending Health Care Coverage

to the Low-Income Population:

The Influence of the Wisconsin BadgerCare

Program on Labor Market Outcomes

Barbara Wolfe

Thomas Kaplan

Robert Haveman

Yoon Young Cho

March 2005 


\title{
Extending Health Care Coverage to the Low-Income Population: The Influence of the Wisconsin BadgerCare Program on Labor Market Outcomes
}

\author{
Barbara Wolfe \\ University of Wisconsin-Madison \\ and IZA Bonn \\ Thomas Kaplan \\ University of Wisconsin-Madison \\ Robert Haveman \\ University of Wisconsin-Madison \\ and IZA Bonn \\ Yoon Young Cho \\ University of Wisconsin-Madison
}

Discussion Paper No. 1546

March 2005

IZA

P.O. Box 7240

53072 Bonn

Germany

Phone: $+49-228-3894-0$

Fax: +49-228-3894-180

Email: iza@iza.org

\begin{abstract}
Any opinions expressed here are those of the author(s) and not those of the institute. Research disseminated by IZA may include views on policy, but the institute itself takes no institutional policy positions.

The Institute for the Study of Labor (IZA) in Bonn is a local and virtual international research center and a place of communication between science, politics and business. IZA is an independent nonprofit company supported by Deutsche Post World Net. The center is associated with the University of Bonn and offers a stimulating research environment through its research networks, research support, and visitors and doctoral programs. IZA engages in (i) original and internationally competitive research in all fields of labor economics, (ii) development of policy concepts, and (iii) dissemination of research results and concepts to the interested public.
\end{abstract}

IZA Discussion Papers often represent preliminary work and are circulated to encourage discussion. Citation of such a paper should account for its provisional character. A revised version may be available directly from the author. 


\section{ABSTRACT}

\section{Extending Health Care Coverage to the Low-Income Population: The Influence of the Wisconsin BadgerCare Program on Labor Market Outcomes*}

The Wisconsin BadgerCare program, which became operational in July 1999, expanded public health insurance eligibility to families with incomes below 185 percent of the U.S poverty line (200 percent for those already enrolled). This eligibility expansion was part of a federal initiative known as the State Children's Health Initiative Program (SCHIP). In this paper, we investigate the effect of Wisconsin's BadgerCare on the labor market outcomes of low-income single mothers. Using a coordinated set of administrative databases, we track three cohorts of mother-only families: those who were receiving cash assistance under the Wisconsin AFDC and TANF programs in September 1995, 1997, and 1999, and who subsequently left welfare. We follow the 19,201 single mothers heading these "welfare leaver" families on a quarterly basis from two years before they left welfare through the end of 2001. We use information on the labor market and welfare history of these women and their household characteristics and macroeconomic environment to analyze the effect of the availability of additional public health coverage on their employment and earnings. We apply multiple methods to investigate these outcomes, comparing across- and within-individual differences. The core finding is that labor earnings increased with the introduction of BadgerCare. This increase was small in absolute dollar value but sizeable in percentage terms.

JEL Classification: I18, J21

Keywords: health care coverage

Corresponding author:

Barbara L. Wolfe

7422 Social Science Building

University of Wisconsin-Madison

WI 53706

USA

Email: wolfe@lafollette.wisc.edu

\footnotetext{
* We thank Dan Ross for his work in getting us the data and Dawn Duren for her technical typing assistance. We thank the Economic Research Initiative on the Uninsured at the University of Michigan and the Health and Society Scholars Program at the University of Wisconsin-Madison (both funded by the Robert Wood Johnson Foundation) and the Annie E. Casey Foundation for their support of this research.
} 


\section{INTRODUCTION}

Soon after implementing the Wisconsin Works (W-2) welfare reform program in September 1997, Wisconsin also began developing its State Children’s Health Insurance Program (SCHIP), “BadgerCare,” which started operation in July 1999. Unlike SCHIP programs in most other states, the BadgerCare program provides income-conditioned health insurance to both adults and children in lowincome families with minor children. It also substantially expands the Medicaid program (in Wisconsin known as Medical Assistance or MA) by providing Medicaid-equivalent health care coverage for both children and adults with incomes below 185 percent of the federal poverty line (200 percent for those already enrolled). As such, the program forms a model that has been studied by several other states and considered at the federal level.

Supporters of BadgerCare promote it for two key reasons. First, the program offers a reduction in the uninsured population, which is heavily concentrated among the low-income population. Second, BadgerCare provides health insurance to assist low-income families, including welfare leavers, in finding and retaining employment in jobs that might not provide health insurance coverage, perhaps supporting and encouraging low-income parents in their efforts to find employment. ${ }^{1}$

In Wolfe et al. (2004), we analyze the extent to which BadgerCare (including its expansion of Medicaid coverage) reduces the proportion of this population that is uninsured. We find that BadgerCare increases public health care coverage by both extending the eligible population and by successfully inducing participation (take-up). This effect offsets the downward trend in the level of Medicaid utilization of these welfare leavers observed prior to the implementation of BadgerCare. As a result,

\footnotetext{
${ }^{1}$ Tommy Thompson, the governor of Wisconsin at the time, said repeatedly that BadgerCare was intended as a complement to $\mathrm{W}-2$ - as a source of health care support for $\mathrm{W}-2$ participants as they moved off cash assistance and into work. On the State of Wisconsin web site, the program is described as follows: "BadgerCare seeks to eliminate barriers to successful employment by providing a transition for families from welfare to private insurance. BadgerCare is based on the premise that health care is essential for working families with children.” http://www.dhfs.state.wi.us/badgercare/html/glance-1.htm
} 
BadgerCare reduces the proportion of this low-income population without health insurance. As a complement to these findings, here we explore the extent to which BadgerCare has achieved its second objective, namely to improve the labor market performance of these women. Specifically, we study the effect of BadgerCare on the employment decisions and labor earnings of these low-income welfare leavers.

We hypothesize that earnings and work effort will increase with the introduction of BadgerCare. More specifically we expect that among leavers who have worked, the availability of BadgerCare, with its publicly subsidized insurance available to those with incomes up to 200 percent of the poverty line, ${ }^{2}$ will increase both labor earnings and hours worked for three reasons. First, we hypothesize that, with BadgerCare in effect, women with low earnings recognize that working and earning at their expected wage rate is unlikely to lead to the loss of health insurance coverage. Hence, the incentive to work more hours or to try to earn a raise is increased by the presence of BadgerCare. Second, those women whose earnings allowed them to remain eligible for Medicaid (or allowed their children to be eligible for Medicaid) should be more likely to increase their hours worked and their earnings because of the presence of BadgerCare. That is, women who are employed but earning below the Medicaid eligibility limit may fear the loss of health insurance because of increased work or earnings without BadgerCare in place, but not with access to BadgerCare. Third, with BadgerCare in place, women with higher earnings who are not eligible for Medicaid but are eligible for BadgerCare would not be constrained from seeking employment with employers not offering health insurance benefits, which may lead both to increased hours worked and higher earnings. In all of these hypotheses, we do not expect BadgerCare to influence earnings and employment of those with no work history, since we believe they face more fundamental obstacles to their participation in the work force than the availability of health insurance.

\footnotetext{
2 Technically, in order to establish eligibility a woman's earnings must be below 185 percent of the FPL; once enrolled, she may remain on BadgerCare while her earnings are below 200 percent of the FPL.
} 
In this paper, then, we examine the magnitude of the hypothesized positive effect of BadgerCare on the employment and earnings of a sample of low-income working mothers. In the next section, we briefly summarize the main characteristics of BadgerCare and its impact on health care coverage. Section 3 describes the data used for this research and presents some descriptive statistics focusing on labor market outcomes. Section 4 presents our empirical model and tests our hypothesis using multiple approaches. Section 5 discusses the results from our estimation. Section 6 concludes the study.

\section{THE BADGERCARE PROGRAM}

In September 1997, Wisconsin eliminated its cash income support program, Aid to Families with Dependent Children (AFDC), replacing it with Wisconsin Works (W-2). Although W-2 removes the entitlement to cash income support that existed under AFDC, it ensures that all working-age adults who have incomes at or below 115 percent of the poverty line and who are parents of minor children have the opportunity to participate in work activities. Moreover, the state supports these activities with cash grants that are contingent on participation in the work activities, child-care assistance, and subsidized health insurance. $^{3}$

As a tool to subsidize health insurance for these low-income working mothers, Wisconsin has also implemented BadgerCare in response to the federal State Children’s Health Insurance Program (SCHIP). This federal program was originally intended to increase health insurance coverage among

\footnotetext{
${ }^{3} \mathrm{~W}-2$ work activities are arrayed in four tiers. In the highest tier, the most work-ready have standard jobs and are eligible for many services (including help in finding a better job, child care subsidies, and health insurance) as long as their earnings remain below eligibility thresholds. The next tier (which generally enrolls few people) provides subsidized jobs for those not quite job-ready. Participants in this tier are also eligible for noncash benefits. The third tier includes those not ready for private-sector jobs; they are placed in "community service" jobs funded by the W-2 agency. Participants are paid for their community service, but they are not eligible for the EITC, since the cash they receive is viewed as a grant and not as earnings. Those least able to work are in the fourth tier ("transitional jobs"). They are required to engage in productive activities (which may take a number of forms, including caring for a disabled child or participating in alcohol or drug abuse counseling), and also receive a grant. In a major departure from the AFDC program that preceded it, participants who are in the lower two tiers of W-2 (and therefore receive a grant for work done, rather than a wage payment) are provided the same level of support for full-time, full-year work regardless of family size. All program participants have a "Financial and Employment Planner" (or FEP) who advises them of their work options, assists them in choosing among these options, and helps them find child care, transportation, and other necessities.
} 
children living in low-income families who were not eligible for Medicaid. The Wisconsin BadgerCare program adds extended health coverage to adults to the extended coverage for children. ${ }^{4}$

By expanding the eligibility level for public health insurance coverage in Wisconsin to 200 percent of the federal poverty line, BadgerCare has significantly lowered the proportion of the lowincome population without health care coverage. In Wolfe et al. (2004), we find that the proportion of all leavers without health insurance was reduced on average by 15 percentage points for both cohorts of leavers. In addition we found that the proportion of the eligible population of welfare leavers in 1995 covered by public health insurance increased by 24-29 percentage points from pre-to post BadgerCare. For those who left welfare in 1997, the percentage with public insurance increased by $2-4$ percentage points. We also find very limited evidence of crowd out of private coverage.

\section{DATA AND DESCRIPTIVE STATISTICS}

Data

The analysis reported here is based on administrative data from the state of Wisconsin. We merge Wisconsin data from: (1) the Client Assistance for Reemployment and Economic Support (CARES) system, which includes information collected in administering AFDC, W-2, and related means-tested programs, (2) the Computer Reporting Network (CRN) system, the precursor of CARES, providing earlier AFDC administrative data useful for constructing an AFDC history for each case, and (3) the Unemployment Insurance (UI) system, which includes quarterly information on earnings and employers. (Appendix 1 provides details of the data sets and the variables used.)

These data include all women who were receiving assistance under the AFDC-Regular or W-2 programs in September of 1995, 1997, and 1999, and who were listed as the "case head" (without the

\footnotetext{
${ }^{4}$ States have much discretion in designing their SCHIP programs. Among other choices, they can expand their Medicaid program, establish a wholly separate program, or combine an expanded Medicaid program with a separate program. Eight states, including Wisconsin, have obtained waivers that enable them to extend benefits to parents.
} 
father of any of the children also listed). We select from these participants those women who exited cash assistance within three months of our initial observation date and remained off the welfare caseload for at least two consecutive months. (Our samples include some women who returned to welfare within the next calendar year.)

Table 1 shows the characteristics of each cohort of AFDC recipients and leavers in the quarter of their exit. The observations included in our analysis consist of the 8,042, 8,162, and 2,997 women who left AFDC during the last quarters of 1995, 1997, and 1999, respectively. The rates of exit are 16, 40, and 41 percent for the three cohorts. ${ }^{5}$

Given earlier reforms and substantial declines in the caseload, we would expect women receiving benefits in 1997 and 1999 to have greater barriers to independence than those receiving benefits in 1995. The statistics in Table 1 are generally consistent with this expectation: the proportions of women with low education and work experience, large numbers of children, and a child with significant disabilities (children on SSI) are more highly represented in the later cohorts than in the 1995 cohort. The case heads in the later cohorts are generally younger than in the 1995 cohort. Perhaps owing to their relative youth, the 1999 cohort contain a lower percentage of cases that had been on welfare during most of the previous two years.

${ }^{5}$ Wisconsin began work-based welfare reforms in the late 1980s and implemented several major reforms in the mid-1990s before PRWORA. These include a Parental and Family Responsibility initiative and a Two-Tier AFDC Benefit Demonstration in 1994 (both initiatives covered four counties and both included Milwaukee County, by far the state's largest) and the Work Not Welfare program in two counties in 1995. The women in the 1995 cohort left cash assistance before Wisconsin implemented key statewide work-focused welfare reforms in September 1997; nevertheless, a climate of reform already existed. The 1997 cohort left cash assistance after the W-2 program had been transformed by waiver-based reforms and during its initial implementation. The final cohort, those who left cash assistance in 1999, left a W-2 program that retained its emphasis on work but had added substantial work supports in the form of child care and family health insurance. 
Table 1

Characteristics of AFDC-Regular Caseload and Leavers in Wisconsin (cases active in September 1995, September 1997, and September 1999)

\begin{tabular}{|c|c|c|c|c|c|c|}
\hline & \multicolumn{2}{|c|}{1995} & \multicolumn{2}{|c|}{1997} & \multicolumn{2}{|c|}{1999} \\
\hline & Total $^{\mathrm{a}}$ & Leavers $^{\mathrm{b}}$ & Total $^{\mathrm{a}}$ & Leavers $^{\mathrm{b}}$ & Total $^{\mathrm{a}}$ & Leavers $^{\mathrm{b}}$ \\
\hline$\overline{\text { Total }(\mathrm{N})}$ & 49,605 & 8,042 & 20,608 & 8,162 & 7,363 & 2,997 \\
\hline \multicolumn{7}{|l|}{ Region } \\
\hline Milwaukee & 54.6 & 38.8 & 74.9 & 55.3 & 82.3 & 77.2 \\
\hline Other urban & 29.6 & 36.7 & 17.7 & 30.8 & 13.0 & 17.1 \\
\hline Rural & 15.8 & 24.5 & 7.4 & 13.9 & 4.7 & 5.7 \\
\hline \multicolumn{7}{|l|}{ Case Head's Age } \\
\hline $18-24$ & 36.0 & 32.2 & 37.3 & 37.9 & 39.7 & 41.4 \\
\hline $25-29$ & 23.8 & 24.0 & 22.4 & 23.3 & 20.3 & 23.16 \\
\hline $30-39$ & 32.1 & 34.9 & 30.7 & 30.3 & 28.9 & 26.9 \\
\hline $40+$ & 8.1 & 9.0 & 9.6 & 8.5 & 11.1 & 8.5 \\
\hline \multicolumn{7}{|l|}{ Education } \\
\hline$<11$ years & 24.3 & 18.9 & 29.4 & 24.7 & 29.6 & 27.4 \\
\hline 11 yearsg & 19.3 & 14.9 & 25.0 & 21.7 & 28.1 & 28.0 \\
\hline 12 years & 42.1 & 47.9 & 36.0 & 40.8 & 34.1 & 35.5 \\
\hline$>12$ years & 14.3 & 18.4 & 9.6 & 12.8 & 82.2 & 9.1 \\
\hline \multicolumn{7}{|l|}{ Race } \\
\hline White & 40.4 & 53.6 & 22.2 & 34.8 & 17.5 & 19.6 \\
\hline African American & 42.1 & 30.3 & 57.1 & 43.9 & 64.4 & 62.5 \\
\hline Hispanic & 7.0 & 6.8 & 8.4 & 8.6 & 6.5 & 5.9 \\
\hline Other & 4.4 & 3.8 & 4.2 & 5.2 & 1.4 & 1.7 \\
\hline Unknown & 6.0 & 5.5 & 8.1 & 7.5 & 10.1 & 10.3 \\
\hline \multicolumn{7}{|l|}{ Number of Own and Foster Children } \\
\hline 1 & 39.0 & 46.8 & 33.1 & 35.3 & 37.0 & 35.8 \\
\hline 2 & 29.7 & 30.2 & 29.0 & 29.8 & 29.3 & 29.4 \\
\hline $3+$ & 31.3 & 23.0 & 37.9 & 34.9 & 33.6 & 34.7 \\
\hline \multicolumn{7}{|l|}{ Age of Youngest Child } \\
\hline$<1$ year & 18.5 & 14.7 & 23.5 & 26.8 & 30.6 & 38 \\
\hline 1 year & 17.1 & 14.0 & 17.7 & 17.0 & 13.9 & 12.7 \\
\hline 2 years & 13.1 & 12.6 & 11.2 & 10.2 & 9.9 & 9.1 \\
\hline $3-5$ years & 24.1 & 25.9 & 21.7 & 20.9 & 17.6 & 16.2 \\
\hline 6-11 years & 19.4 & 22.4 & 18.6 & 18.3 & 19.7 & 17.1 \\
\hline 12-18 years & 7.8 & 10.4 & 7.3 & 6.9 & 9.3 & 6.9 \\
\hline \multicolumn{7}{|l|}{ Other Household Members } \\
\hline Other children only & 2.6 & 1.8 & 4.0 & 3.0 & 6.1 & 6.6 \\
\hline Other adults only & 21.0 & 23.3 & 18.6 & 19.7 & 17.7 & 16.8 \\
\hline Other adults and other children & 7.5 & 8.2 & 7.5 & 7.7 & 6.3 & 6.8 \\
\hline
\end{tabular}

(table continues) 
Table 1, continued

\begin{tabular}{|c|c|c|c|c|c|c|}
\hline & \multicolumn{2}{|c|}{1995} & \multicolumn{2}{|c|}{1997} & \multicolumn{2}{|c|}{1999} \\
\hline & Total $^{\mathrm{a}}$ & Leavers $^{\mathrm{b}}$ & Total $^{\mathrm{a}}$ & Leavers $^{\mathrm{b}}$ & Total $^{\mathrm{a}}$ & Leavers $^{\mathrm{b}}$ \\
\hline Child on SSI & 9.1 & 6.3 & 11.6 & 8.7 & 11.6 & 10.2 \\
\hline \multicolumn{7}{|l|}{ Start of Current Spell ${ }^{\mathrm{c}}$} \\
\hline 0-3 months ago & 14.8 & 27.7 & 17.0 & 20.7 & 34.0 & 36.4 \\
\hline 4-6 months ago & 6.8 & 10.3 & 9.8 & 11.6 & 19.1 & 22.1 \\
\hline 7-9 months ago & 5.2 & 6.6 & 6.8 & 7.7 & 9.9 & 10.7 \\
\hline 10-12 months ago & 4.4 & 5.4 & 5.3 & 6.0 & 6.3 & 6.1 \\
\hline 13-18 months ago & 7.1 & 7.0 & 6.4 & 6.7 & 6.3 & 6.4 \\
\hline 19-24 months ago & 6.1 & 5.1 & 4.6 & 4.7 & 3.6 & 3.2 \\
\hline$>24$ months ago & 55.7 & 37.9 & 50.2 & 42.5 & 20.8 & 15.2 \\
\hline \multicolumn{7}{|c|}{$\begin{array}{l}\text { Number of Months Received Welfare } \\
\text { in the Two Years Prior to September } \\
1995 \text { and } 1997^{c}\end{array}$} \\
\hline 6 months or less & 10.0 & 16.3 & 8.5 & 12.4 & 27.3 & 32.1 \\
\hline 7-12 months & 9.1 & 13.3 & 9.4 & 11.7 & 28.1 & 19.6 \\
\hline 13-18 months & 12.0 & 16.9 & 14.4 & 16.2 & 19.4 & 20.3 \\
\hline 19-24 months & 68.9 & 53.5 & 67.7 & 59.6 & 35.3 & 28.0 \\
\hline \multicolumn{7}{|c|}{$\begin{array}{l}\text { Number of Quarters with Earnings in } \\
\text { the Two Years Prior to September } \\
1995 \text { and } 1997^{c}\end{array}$} \\
\hline None & 29.0 & 14.5 & 22.4 & 13.8 & 18.8 & 11.8 \\
\hline 1-3 quarters & 31.9 & 29.0 & 34.4 & 33.9 & 31.8 & 29.6 \\
\hline 4-7 quarters & 29.1 & 37.2 & 33.9 & 38.7 & 39.1 & 44.5 \\
\hline 8 quarters & 10.0 & 19.2 & 9.4 & 13.6 & 10.3 & 14.1 \\
\hline \multicolumn{7}{|c|}{$\begin{array}{l}\text { Total Earnings in the Two Years } \\
\text { Prior to September } 1995 \text { and } 1997^{c}\end{array}$} \\
\hline$<\$ 500$ & 39.3 & 20.7 & 33.4 & 22.5 & 29.4 & 20.8 \\
\hline$\$ 500-\$ 2,499$ & 18.7 & 15.5 & 21.7 & 21.4 & 20.0 & 19.7 \\
\hline$\$ 2,500-\$ 7,499$ & 20.8 & 25.5 & 24.0 & 28.0 & 22.8 & 24.8 \\
\hline$\$ 7,500$ or more & 21.3 & 38.4 & 20.9 & 28.1 & 27.7 & 34.7 \\
\hline
\end{tabular}

${ }^{a}$ Recipients in September.

${ }^{\mathrm{b}}$ Left in the last quarter of the year.

' Sample in the first two columns includes case heads who were 18 or older in October 1995 (N=46,047 and 7,608); the third and fourth columns include those 18 or older in October 1997 ( $\mathrm{N}=18,689$ and 7,434); the fifth and sixth columns include those 18 or over in October $1999(=7,363$ and 2,997) 
With these demographic and income data, we identify all families from among the population of leavers in each of the three cohorts $(1995,1997,1999)$ that are eligible for BadgerCare/MA benefits, using an income-based algorithm that calculates MA eligibility for each household member based on the poverty-related criteria for eligibility. Household earnings are calculated as the total earnings reported in the UI database, with deductions of $\$ 90 /$ month for work expenses and $\$ 30 /$ month plus $1 / 3$ of the remaining earnings.

Using these data, we track these "leaver" families on a quarterly basis from two years before they left welfare through the end of 2001. Hence, we are able to utilize the labor market information and welfare history of these women in analyzing the outcomes. Our analysis covers the period from the $4^{\text {th }}$ quarter of the year they left welfare through the $4^{\text {th }}$ quarter of 2001: 25 quarters for the 1995 cohort, 17 quarters for the 1997 cohort, and 9 quarters for the 1999 cohort.

\section{$\underline{\text { Descriptive Analysis }}$}

Since BadgerCare was introduced in the $3^{\text {rd }}$ quarter of 1999, the 1999 cohort experiences BadgerCare immediately upon exit from welfare. Hence, we use information on the 1995 and 1997 cohorts to investigate the exogenous effect of introducing BadgerCare. 
Figure 1.

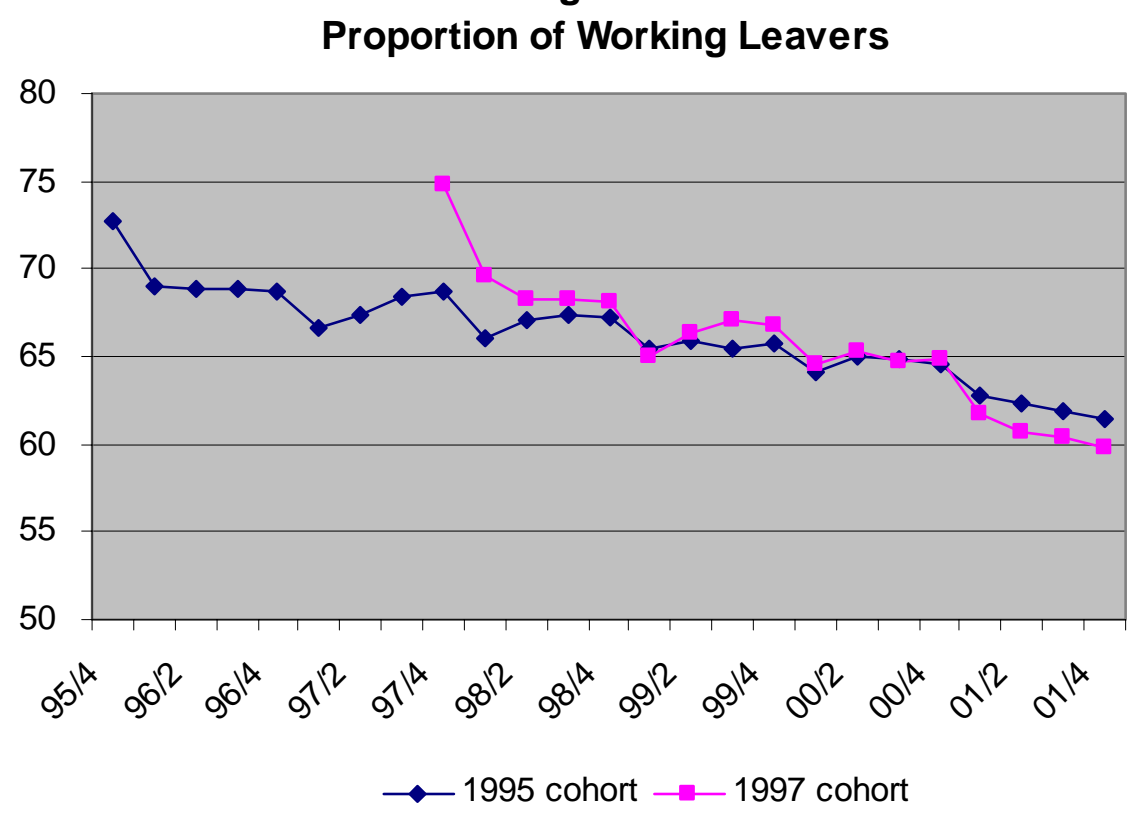

Figure 1 shows the proportion of working leavers from the 1995 and 1997 cohorts during each quarter from the time of exit until 2001. For both cohorts, the level of employment declines steadily from about 73-75 percent in the quarter after leaving to about 60-62 percent by 2001 . The more rapid decline in employment for the 1997 cohort suggests that the women leaving welfare in that year were more vulnerable to the softening of the economy after 2000 than were those in the 1995 cohort, consistent with their characteristics suggesting greater barriers to independence. For both cohorts, an increase in employment is observed in the $4^{\text {th }}$ quarter of most years. 
Figure 2. Mean Quarterly Earnings of Leavers 95 cohort

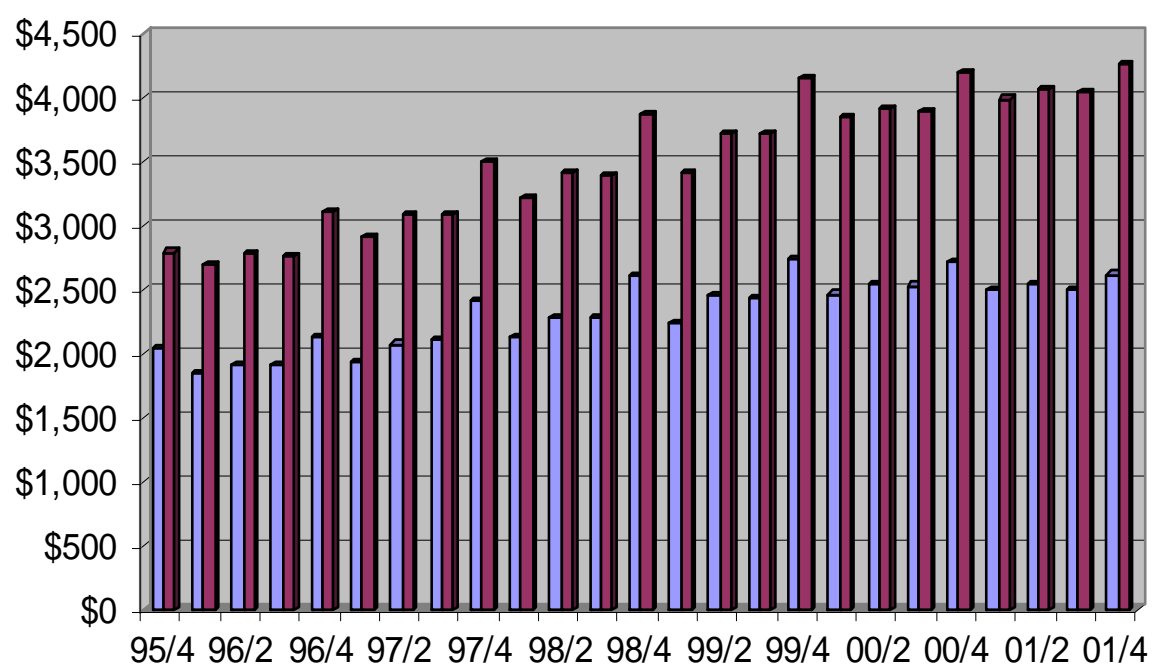

97 cohort

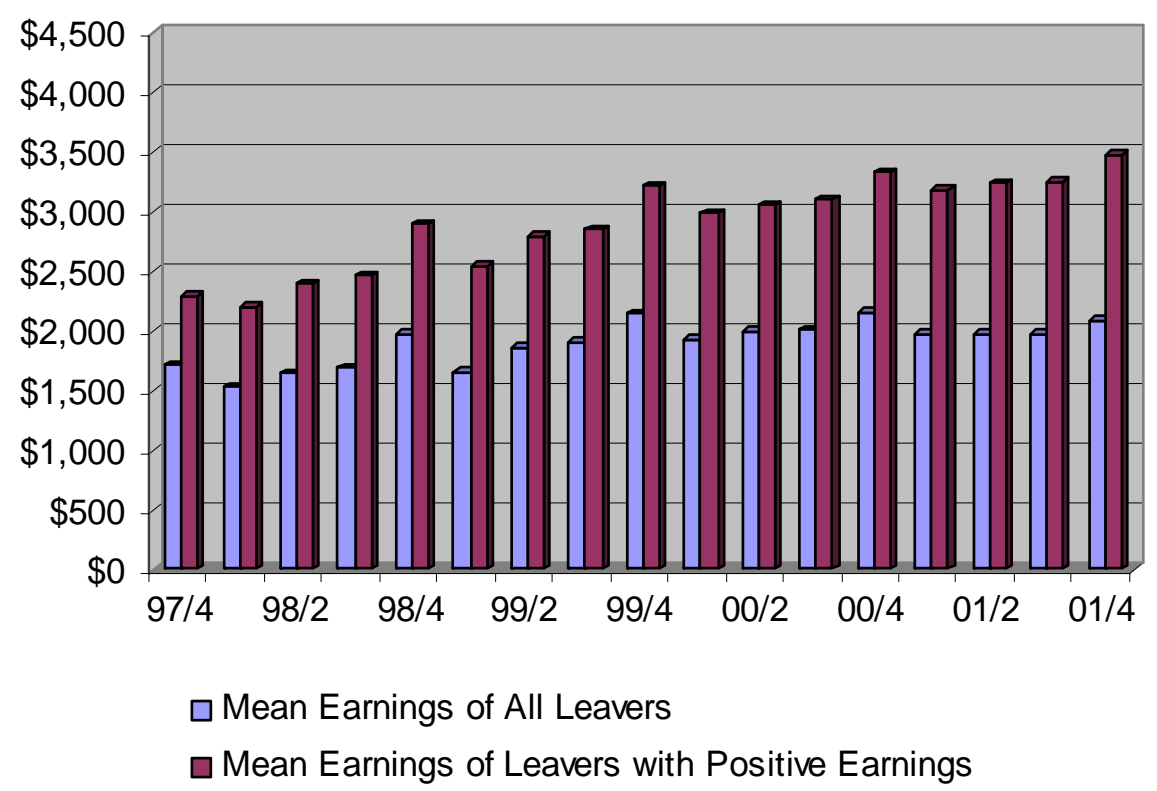

Figure 2 presents the quarterly earnings of both cohorts among all leavers and among those with positive earnings. Average earnings increase steadily for both cohorts, although the increase is less pronounced among all leavers than among those with positive earnings, reflecting the reduction in overall employment levels shown in Figure 1. The earnings of the 1995 cohort exceed those of the 1997 cohort 
through the entire period, reflecting the superior human capital characteristics of the earlier cohort. For both cohorts, the earnings of working leavers increase more rapidly for the 1995 than the 1997 cohort, again consistent with the greater labor market qualifications of the 1995 cohort.

The average quarterly earnings for the entire 1995 cohort increase from about \$2000 when they exit the welfare program in the $4^{\text {th }}$ quarter of 1995 to about $\$ 2,700$ by 2000 . Due to the economic recession during years of 2000 and 2001, ${ }^{6}$ average quarterly earnings level off at about \$2,500 dollars beginning in 2000. Average quarterly earnings for the entire 1997 cohort are about $\$ 1,700$ at the time of exit in the $4^{\text {th }}$ quarter of 1997 , and grow to $\$ 2,100$ by 2000. During 2000 and 2001, the 1997 cohort is also affected by the recession, and their quarterly earnings also remain stagnant during this period.

The earnings patterns for those who are employed are somewhat different. For the 1995 cohort, quarterly earnings of working leavers increased from about $\$ 2800$ in 1996 to over $\$ 4200$ by 2002. For the 1997 cohort, quarterly earnings of working leavers increased from about \$2200 in 1998 to nearly \$3500 by 2002. For both cohorts, the recession of 2000 and 2001 slowed quarterly earnings growth, but failed to eliminate it.

In sum, for both cohorts employment rates tend to decrease during the years after leaving welfare, whereas average earnings tend to rise persistently for those who work. For all leavers, average earnings grow for both cohorts until the recession of 2000-2001, at which time the level of earnings remains nearly unchanged. Superior labor market outcomes are observed for the 1995 cohort than for the 1997 cohort; the rate of erosion of the employment rate is lower for the 1995 cohort, and earnings growth is greater. Because changes in macroeconomic conditions directly affect these employment and earnings patterns, it is difficult to discern the independent effect of BadgerCare from these trends. We now turn our attention to that issue.

\footnotetext{
${ }^{6}$ The average unemployment rate of all counties in Wisconsin increased from 3.91 percent in 1999 to 4.19 percent in 2000 and 5.24 percent in 2001.
} 


\section{MODELING THE EFFECT OF BADGERCARE}

\section{The Effects of BadgerCare on the Employment Outcome}

Consider a latent variable $y_{i t}^{*}$ which determines participation in labor market. The decision equation is specified as:

$$
\begin{aligned}
& y_{i t}^{*}=\beta^{\prime} x_{i t}+\alpha_{0} Q_{t}+\alpha_{1} B C_{t}+v_{i t}, \\
& y_{i t}=\left\{\begin{array}{l}
1 \text { if } y_{i t}^{*}>0 \\
0 \text { if } y_{i t}^{*} \leq 0
\end{array}\right.
\end{aligned}
$$

where $i$ indexes individuals, $t$ indexes time period, and $y_{i t}$ is the binomial and observed dependent variable measuring employment. The explanatory variables influencing participation in labor market include demographic characteristics, $x_{i t}$, number of quarters since exit, $Q_{t}$, and an indicator of the introduction of BadgerCare, $B C_{t}$. The error term $v_{i t}$ is assumed to follow a normal distribution controlling for all observed independent variables:

$$
v_{i t} \mid x_{i t}, Q_{t}, B C_{t} \sim N(0,1)
$$

Hence, the probability of working is shown as:

$$
\operatorname{Pr}\left(y_{i t}=1 \mid x_{i t}, Q_{t}, B C_{t}\right)=\Phi\left(\beta^{\prime} x_{i t}+\alpha_{0} Q_{t}+\alpha_{1} B C_{t}\right) \text {, }
$$

and the log likelihood function is:

$$
\log L=\sum_{i, t}\left[y_{i t} \log \left\{\Phi\left(\beta^{\prime} x_{i t}+\alpha_{0} Q_{t}+\alpha_{1} B C_{t}\right)\right\}+\left(1-y_{i t}\right) \log \left\{1-\Phi\left(\beta^{\prime} x_{i t}+\alpha_{0} Q_{t}+\alpha_{1} B C_{t}\right)\right\}\right]
$$

With these assumptions, a pooled probit estimation of the effect of BadgerCare, $\alpha_{1}$, is consistent and asymptotically normal without any further assumptions. The variance of the estimate is obtained taking into account repeated observations of the same person over time.

Alternatively, the unobserved individual characteristics that persist over time may affect the decision to participate in the labor market. In this case, the error term from the model above can be decomposed into the persistent and random components: $v_{i t}=\theta_{i}+\eta_{i t}$. In this case, the effect of 
BadgerCare, $\alpha_{i t}$, can be estimated controlling for unobserved effects. We assume that these unobserved individual characteristics, $\theta_{i}$, form a random variable that follows the conditional distribution $\theta_{i} \mid x_{i t}, Q_{t}, B C_{t} \sim G(\cdot)$, where $G$ is the cumulative density function of the normal distribution. With this distributional assumption on $\eta_{i t}$, the likelihood function can be constructed and a random effect logit model can be estimated.

The random effects model of the probability of employment that we estimate is:

$$
\operatorname{Pr}\left(y_{i t}=1 \mid x_{i t}, Q_{t}, B C_{t}, \theta_{i}\right)=\Lambda\left(\beta^{\prime} x_{i t}+\alpha_{0} Q_{t}+\alpha_{1} B C_{t}+\theta_{i}\right) \text {, }
$$

and the underlying likelihood function is:

$\log L=\sum_{i} \log \int \prod_{t}\left\{\Lambda\left(\beta^{\prime} x_{i t}+\alpha_{0} Q_{t}+\alpha_{1} B C_{t}+\theta\right)\right\}^{y_{i t}}\left\{1-\Lambda\left(\beta^{\prime} x_{i t}+\alpha_{0} Q_{t}+\alpha_{1} B C C_{t}+\theta\right)\right\}^{1-y_{i t}} d G(\theta \mid x, Q, B C)$

where $\Lambda$ is the cumulative density function of standard logistic. The maximum likelihood estimate of the random effects logit regression provides a consistent estimate of the effect of BadgerCare on labor force participation with a large number of observations.

\section{The Effects of BadgerCare on Earnings}

Consider a dependent variable $y_{i t}$ which is the labor earnings of each individual. Individual earnings are specified as:

$$
y_{i t}=\beta^{\prime} x_{i t}+\alpha_{0} Q_{t}+\alpha_{1} B C_{t}+v_{i t}
$$

where $i$ indexes individuals, $t$ indexes time period, $x_{i t}$ is individual and family characteristics, $Q_{t}$ is the number of quarters since exit, and $B C_{t}$ is an indicator of the introduction of BadgerCare. The error term here, $v_{i t}$, is assumed to be serially uncorrelated.

We conduct this OLS analysis with robust standard errors to take account of repeated observations of the same individual. The coefficient of the $B C_{t}, \alpha_{1}$, captures the effect of BadgerCare on 
the dependent variable without further assumptions. However, if the error terms are serially correlated, the estimate from OLS is not consistent.

It is likely that there are the unobserved individual characteristics that persist over time and may affect labor earnings. In this case, the error term from the model above can be decomposed into the persistent and random components: $v_{i t}=\theta_{i}+\eta_{i t}$. In this case, the effect of BadgerCare, $\alpha_{i t}$, can be estimated controlling for unobserved effects by differencing out the unobservable characteristics. Specifically, the following equations show the wage earnings equation including the unobservable characteristics and the average of it within individuals over time.

$$
\begin{aligned}
& y_{i t}=\beta^{\prime} x_{i t}+\alpha_{0} Q_{t}+\alpha_{1} B C_{t}+\theta_{i}+\eta_{i t} \\
& \overline{y_{i}}=\beta^{\prime} \overline{x_{i}}+\alpha_{0} \overline{Q_{t}}+\alpha_{1} \overline{B C_{t}}+\theta_{i}
\end{aligned}
$$

After differencing out the unobserved characteristics from the original equation, the averaged equation whose dependent and independent variables are demeaned is used in estimation, as the following equations show. The estimate of the effect of BadgerCare, $\alpha_{0}$, from this equation is now consistent.

$$
\begin{aligned}
& y_{i t}-\overline{y_{i}}=\beta^{\prime}\left(x_{i t}-\overline{x_{i}}\right)+\alpha_{0}\left(Q_{t}-\overline{Q_{t}}\right)+\alpha_{1}\left(B C_{t}-\overline{B C_{t}}\right)+\eta_{i t} \\
& y_{i t}^{*}=\beta^{\prime} x_{i t}^{*}+\alpha_{0} Q_{t}^{*}+\alpha_{1} B C_{t}^{*}+\eta_{i t}
\end{aligned}
$$

\section{RESULTS}

Making use of rich information on individual and household characteristics, we introduce into the estimation a large number of independent variables to reflect factors potentially related to labor market outcomes. These characteristics include demographic variables such as race, education, age, and work and welfare history. The characteristics also include household variables such as the number of children, number of other adults in the household, the presence of any child in the family on SSI and the age of the youngest child.

In addition to individual and household characteristics, we also utilize the variation of locality characteristics by adding current area of residence, the current unemployment rate of each county of 
residence, and the proportion of female-headed families in the woman's neighborhood. The general time effect on the outcome is captured by the number of quarters since exit. Finally, to capture the independent effect of BadgerCare on this outcome, we include a dummy variable for whether or not BadgerCare is available.

The Effects of BadgerCare on the Employment Decision

Table 2 presents our random effects estimates of parameters with the binary employment outcome as a dependent variable; standard errors are adjusted for repeated observation of each individual. Separate estimates are presented for the 1995 and 1997 cohorts using probit estimation, as described above. The estimation is run over those leavers who have any work experience during the two years prior to leaving welfare; for the 1995 cohort the estimation excludes the first eight quarters after leaving welfare, so as to yield estimates over the same period (quarter 4, 1997 to quarter 4, 2001) for both cohorts. $^{7}$

The sign and magnitude of the control variables are, in general, as expected. The contemporaneous unemployment rate is negatively and significantly related to working for both cohorts. The negative sign on the quarters-since-exit variable is consistent with Figure 1, above. The coefficient on the lagged work variable (introduced to capture unobserved factors tied to longer run propensity to work and also to avoid the effect of serial correlation) is positive and highly significant, as expected. Perhaps surprisingly the variables for history of welfare participation suggest that those women with longer histories on cash welfare are more likely to work after leaving welfare. Those who worked more quarters prior to exit are far more likely to work after exit. (The omitted category is worked just 3 or fewer quarters prior to exit.) The effect of the introduction of BadgerCare is positive and statistically significant for the 1997 cohort, but appears to have little impact for the 1995 cohort. The coefficient on the 1997

\footnotetext{
${ }^{7}$ We proceed in this way to avoid contaminating the results with differences in the macro economy.
} 
Table 2

Probit Estimation of Employment, September 1997-December 2001

\begin{tabular}{|c|c|c|c|c|c|c|c|c|}
\hline \multirow[b]{3}{*}{ Likelihood of Working } & \multicolumn{4}{|c|}{1995 Cohort } & \multicolumn{4}{|c|}{1997 Cohort } \\
\hline & \multicolumn{3}{|c|}{ Standard } & \multirow[b]{2}{*}{$\mathrm{P}>|\mathrm{z}|$} & \multicolumn{3}{|c|}{ Standard } & \multirow[b]{2}{*}{$\mathrm{P}>|\mathrm{z}|$} \\
\hline & Coefficient & Error & $\mathrm{z}$ & & Coefficient & Error & $\mathrm{z}$ & \\
\hline Constant & -3.71 & 0.38 & -9.70 & 0.00 & -2.89 & 0.24 & -11.95 & 0.00 \\
\hline Age of case head & 0.15 & 0.02 & 7.01 & 0.00 & 0.16 & 0.01 & 10.57 & 0.00 \\
\hline Age of case head squared & 0.00 & 0.00 & -7.02 & 0.00 & 0.00 & 0.00 & -11.27 & 0.00 \\
\hline Lagged work & 3.07 & 0.03 & 109.62 & 0.00 & 2.46 & 0.02 & 107.75 & 0.00 \\
\hline Unrelated children in household & -0.07 & 0.09 & -0.76 & 0.45 & -0.19 & 0.07 & -2.79 & 0.01 \\
\hline Child on SSI & -0.43 & 0.11 & -3.93 & 0.00 & -0.14 & 0.07 & -1.94 & 0.05 \\
\hline Other adult in household & 0.02 & 0.06 & 0.24 & 0.81 & 0.01 & 0.05 & 0.11 & 0.91 \\
\hline More than 1 spell on AFDC/TANF & -0.07 & 0.06 & -1.12 & 0.27 & -0.23 & 0.05 & -4.86 & 0.00 \\
\hline Case head's education $=12$ years & 0.25 & 0.06 & 4.37 & 0.00 & 0.26 & 0.04 & 6.08 & 0.00 \\
\hline Case head's education $=>12$ years & 0.23 & 0.08 & 3.04 & 0.00 & 0.30 & 0.06 & 4.68 & 0.00 \\
\hline Black & -0.15 & 0.08 & -1.85 & 0.06 & -0.09 & 0.06 & -1.60 & 0.11 \\
\hline Hispanic & 0.03 & 0.13 & 0.24 & 0.81 & -0.07 & 0.08 & -0.89 & 0.37 \\
\hline Other race/ethnicity & -0.23 & 0.14 & -1.57 & 0.12 & -0.03 & 0.11 & -0.23 & 0.82 \\
\hline Unknown race/ethnicity & -0.10 & 0.12 & -0.80 & 0.42 & -0.05 & 0.08 & -0.67 & 0.50 \\
\hline Had earnings in $4-7$ of prior 8 quarters & 0.62 & 0.06 & 10.63 & 0.00 & 0.61 & 0.04 & 14.07 & 0.00 \\
\hline Had earnings in all 8 quarters & 1.49 & 0.08 & 18.83 & 0.00 & 1.26 & 0.07 & 19.05 & 0.00 \\
\hline On AFDC 7-12 months & 0.19 & 0.10 & 1.99 & 0.05 & 0.16 & 0.07 & 2.11 & 0.04 \\
\hline On AFDC 13-18 months & 0.56 & 0.10 & 5.80 & 0.00 & 0.26 & 0.08 & 3.48 & 0.00 \\
\hline On AFDC 19-24 months & 0.61 & 0.08 & 7.74 & 0.00 & 0.28 & 0.06 & 4.39 & 0.00 \\
\hline Lives in a rural county & 0.12 & 0.07 & 1.77 & 0.08 & -0.04 & 0.07 & -0.56 & 0.58 \\
\hline Lives in Milwaukee county & 0.37 & 0.08 & 4.56 & 0.00 & 0.23 & 0.06 & 4.11 & 0.00 \\
\hline $\begin{array}{l}\text { Percent of households that are female-headed in } \\
\text { county }\end{array}$ & -0.22 & 0.24 & -0.91 & 0.36 & -0.07 & 0.16 & -0.44 & 0.66 \\
\hline Age of youngest child & 0.00 & 0.00 & 0.45 & 0.66 & 0.00 & 0.00 & -0.71 & 0.48 \\
\hline Number of quarters since exit & -0.02 & 0.00 & -3.61 & 0.00 & -0.03 & 0.00 & -7.29 & 0.00 \\
\hline Two children in household & 0.02 & 0.05 & 0.28 & 0.78 & 0.05 & 0.05 & 0.92 & 0.36 \\
\hline Three or more children in household & 0.09 & 0.06 & 1.57 & 0.12 & -0.09 & 0.05 & -1.75 & 0.08 \\
\hline Quarterly unemployment rate in county & -0.08 & 0.01 & -7.14 & 0.00 & -0.06 & 0.01 & -5.15 & 0.00 \\
\hline BadgerCare available & -0.02 & 0.05 & -0.51 & 0.61 & 0.10 & 0.04 & 2.63 & 0.01 \\
\hline
\end{tabular}


BadgerCare variable indicates that introduction of the program increased employment by 1.33 percentage points for the 1997 cohort.

\section{The Effects of BadgerCare on Earnings}

\section{Ordinary Least Squares Estimates}

Table 3 presents our OLS estimates with quarterly earnings as a dependent variable and with robust standard errors. Again, the first 8 quarters since exit for the 1995 cohort are dropped in order to capture the effect of BadgerCare over the same quarters of analysis for both 1995 and 1997 cohorts. And, as with the employment estimates, the estimates are for a sample of leavers who have any work experience during the two years prior to leaving welfare.

The effects of the independent variables are as expected, and are similar across the cohorts. Education, age, Hispanic, residing in Milwaukee, the number of quarters since exit are positively and significantly related to earnings, while the county unemployment rate and proportion of female heads in

the county are negatively and significantly related to earnings. The general positive time effect is reflected in the variable indicating the number of quarters since exit, which is positive and significant for both cohorts. Those with greater earnings history while on welfare have greater earnings (note again that the omitted category is worked 3 or fewer quarters prior to exit.) And as found in the work estimates, those with longer histories of cash welfare participation also have higher earnings; however this finding is only statistically significant for the 1995 cohort.

The effect of the introduction of BadgerCare is positive and highly statistically significant, and suggests that the BadgerCare program increased the quarterly earnings of the 1995 cohort by about $\$ 72$ per quarter (about 3 percent), and those of 1997 cohort by nearly $\$ 153$ per quarter (about 7 percent).

\section{Fixed Effects Estimates}

To account for the effects of unobserved characteristics on earnings, we present fixed effects regression estimates of the effect of BadgerCare. These estimates are run separately for mothers in the 
Table 3

Ordinary Least Squares Estimation of Earnings, September 1997-December 2001

\begin{tabular}{|c|c|c|c|c|c|c|c|c|}
\hline \multirow[b]{2}{*}{ Wage } & \multicolumn{4}{|c|}{1995 Cohort } & \multicolumn{4}{|c|}{1997 Cohort } \\
\hline & Coefficient & $\begin{array}{c}\text { Robust } \\
\text { Standard } \\
\text { Error }\end{array}$ & $\mathrm{t}$ & $\mathrm{P}>|\mathrm{t}|$ & Coefficient & $\begin{array}{c}\text { Robust } \\
\text { Standard } \\
\text { Error }\end{array}$ & $\mathrm{t}$ & $\mathrm{P}>|\mathrm{t}|$ \\
\hline Constant & -509.13 & 293.45 & -1.73 & 0.08 & -454.07 & 182.75 & -2.48 & 0.01 \\
\hline Age of case head & 118.93 & 17.00 & 7.00 & 0.00 & 107.30 & 11.15 & 9.63 & 0.00 \\
\hline Age of case head squared & -1.78 & 0.25 & -7.23 & 0.00 & -1.69 & 0.18 & -9.39 & 0.00 \\
\hline Unrelated children in household & -76.65 & 90.22 & -0.85 & 0.40 & -80.83 & 66.28 & -1.22 & 0.22 \\
\hline Child on SSI & -352.64 & 109.08 & -3.23 & 0.00 & -122.94 & 71.10 & -1.73 & 0.08 \\
\hline Other adult in household & -36.71 & 59.57 & -0.62 & 0.54 & -22.77 & 46.90 & -0.49 & 0.63 \\
\hline More than 1 spell on AFDC/TANF & -116.19 & 59.39 & -1.96 & 0.05 & -200.16 & 44.97 & -4.45 & 0.00 \\
\hline Case head's education $=12$ years & 468.92 & 53.61 & 8.75 & 0.00 & 517.75 & 39.51 & 13.11 & 0.00 \\
\hline Case head's education $=>12$ years & 1003.26 & 82.43 & 12.17 & 0.00 & 886.95 & 72.15 & 12.29 & 0.00 \\
\hline Black & 177.39 & 84.52 & 2.10 & 0.04 & 80.17 & 53.48 & 1.50 & 0.13 \\
\hline Hispanic & 307.18 & 125.70 & 2.44 & 0.02 & 278.63 & 85.07 & 3.28 & 0.00 \\
\hline Other race/ethnicity & 39.37 & 151.42 & 0.26 & 0.80 & 84.04 & 102.26 & 0.82 & 0.41 \\
\hline Unknown race/ethnicity & -3.23 & 116.74 & -0.03 & 0.98 & 72.52 & 81.31 & 0.89 & 0.37 \\
\hline Had earnings in 4-7 of prior 8 quarters & 476.52 & 58.05 & 8.21 & 0.00 & 393.14 & 41.93 & 9.38 & 0.00 \\
\hline Had earnings in all 8 quarters & 1301.56 & 75.38 & 17.27 & 0.00 & 1009.42 & 60.79 & 16.60 & 0.00 \\
\hline On AFDC for $7-12$ months & 21.53 & 95.85 & 0.22 & 0.82 & 17.94 & 70.03 & 0.26 & 0.80 \\
\hline On AFDC for $13-18$ months & 183.55 & 94.46 & 1.94 & 0.05 & 26.88 & 72.65 & 0.37 & 0.71 \\
\hline On AFDC for 19-24 months & 243.15 & 80.38 & 3.02 & 0.00 & 18.54 & 62.24 & 0.30 & 0.77 \\
\hline Lives in a rural county & -20.46 & 66.16 & -0.31 & 0.76 & -76.17 & 62.16 & -1.23 & 0.22 \\
\hline Lives in Milwaukee county & 711.67 & 85.58 & 8.32 & 0.00 & 560.31 & 55.80 & 10.04 & 0.00 \\
\hline $\begin{array}{l}\text { Percentage of household that are female- } \\
\text { headed in county }\end{array}$ & -604.11 & 256.19 & -2.36 & 0.02 & -440.36 & 157.19 & -2.80 & 0.01 \\
\hline Age of youngest child & 20.01 & 5.16 & 3.87 & 0.00 & 7.39 & 5.21 & 1.42 & 0.16 \\
\hline Number of quarters since exit & 22.38 & 3.75 & 5.97 & 0.00 & 18.21 & 3.33 & 5.46 & 0.00 \\
\hline Two children in household & -135.50 & 63.37 & -2.14 & 0.03 & -11.12 & 56.27 & -0.20 & 0.84 \\
\hline Three or more children in household & -117.32 & 66.46 & -1.77 & 0.08 & -115.43 & 56.36 & -2.05 & 0.04 \\
\hline Quarterly unemployment rate in county & -96.22 & 14.81 & -6.50 & 0.00 & -52.80 & 12.76 & -4.14 & 0.00 \\
\hline BadgerCare available & 71.63 & 25.71 & 2.79 & 0.01 & 152.64 & 22.88 & 6.67 & 0.00 \\
\hline
\end{tabular}


1995 and 1997 cohorts, and the results are shown in Table 4. Note that the fixed effects estimates capture the within individual variation over time. Because the variables included in the model are only those that change over time, the specification is parsimonious. Again, the estimation is run over those leavers who have any work experience during the two years prior to leaving welfare and excludes the first eight quarters after leaving welfare for the 1995 cohort.

For both cohorts, the coefficients on the control variables are as expected-the age of the youngest child, the number of quarters since exit, and having three or more children are positively and significantly related to earnings, while again the unemployment rate in the county of residence is negatively and significantly related to earnings. The coefficients on the BadgerCare variable for both the 1995 and 1997 cohorts are significantly and positively related to the earnings of these women; they suggest that the introduction of BadgerCare led to an increase on average of \$85 per quarter for the 1995 cohort (about 3 percent) and \$136 per quarter for the 1997 cohort (about 6 percent).

\section{VIIII. CONCLUSION}

The enactment of the BadgerCare program in Wisconsin provided a major expansion of health insurance availability, offering coverage to adults in low-income families with children, and increasing the income levels under which coverage is available. In this report, we examined the effects of BadgerCare on the labor market outcomes of low-income women who left cash assistance.

Our estimates indicate that BadgerCare has a positive but small effect on the employment decisions of the single low-income mothers who we study; this effect is statistically significant for only the 1997 cohort. This small employment effect is not unexpected; the BadgerCare program targets those women whose income is above the eligibility cut-off income level of Medicaid and still below 185 percent of the federal poverty line. Hence, the women targeted are likely to be already working in the absence of BadgerCare.

However, both the OLS and the fixed effects estimates indicate that the effect of BadgerCare on the labor earnings of these women is significant and positive. The quantitative effect is not small in 
Table 4

Fixed Effects Estimation of Earnings

\begin{tabular}{|c|c|c|c|c|c|c|c|c|}
\hline \multirow[b]{3}{*}{ Wage } & \multicolumn{4}{|c|}{1995 Cohort } & \multicolumn{4}{|c|}{1997 Cohort } \\
\hline & \multicolumn{3}{|c|}{ Standard } & \multirow[b]{2}{*}{$\mathrm{P}>|\mathrm{t}|$} & \multicolumn{3}{|c|}{ Standard } & \multirow[b]{2}{*}{$\mathrm{P}>|\mathrm{t}|$} \\
\hline & Coefficient & Error & $\mathrm{t}$ & & Coefficient & Error & $\mathrm{t}$ & \\
\hline Constant & -931.69 & 468.72 & -1.99 & 0.05 & 491.02 & 319.16 & 1.54 & 0.12 \\
\hline Age of case head & 176.42 & 21.36 & 8.26 & 0.00 & 124.53 & 15.15 & 8.22 & 0.00 \\
\hline Age of case head squared & -1.96 & 0.26 & -7.58 & 0.00 & -2.65 & 0.21 & -12.55 & 0.00 \\
\hline Age of youngest child & 8.88 & 1.95 & 4.55 & 0.00 & 23.72 & 2.36 & 10.07 & 0.00 \\
\hline Number of quarters since exit & 11.16 & 3.97 & 2.81 & 0.01 & 30.43 & 3.24 & 9.39 & 0.00 \\
\hline Two children in household & -57.28 & 39.07 & -1.47 & 0.14 & 154.02 & 48.39 & 3.18 & 0.00 \\
\hline Three or more children in household & 171.62 & 52.33 & 3.28 & 0.00 & 181.85 & 63.63 & 2.86 & 0.00 \\
\hline Quarterly unemployment rate in county & -80.59 & 5.50 & -14.66 & 0.00 & -69.21 & 5.90 & -11.74 & 0.00 \\
\hline BadgerCare available & 85.17 & 18.49 & 4.61 & 0.00 & 136.06 & 16.90 & 8.05 & 0.00 \\
\hline
\end{tabular}


percentage terms, ranging from 3 to 7 percent of earnings; however, the dollar-valued increment-from \$72-\$153 per quarter-is unlikely to lead to a major improvement in overall economic wellbeing. This increase in earnings can be attributed to the changed incentives created by BadgerCare for these working women — with the program in effect, working women are able to increase their hours of work and their earnings without losing eligibility for public health insurance coverage. Moreover, they are able to seek work, perhaps with greater pay and longer available hours, with employers not offering private health insurance without fear of becoming uninsured. An interesting question is the possible effect of BadgerCare on job duration, and that is a subject for future research. (See Gruber and Madrian, 2001; Moffitt and Wolfe, 1992). 


\section{APPENDIX 1 Sample and Variable Definition}

We extracted data from the CARES database for all women receiving assistance under the AFDC-Regular or W-2 programs in September of 1995, 1997, and 1999 who were listed as the "case head," who did not live with the father of any of the children also listed on the case, who had minor children in the case, and who were at least 18 years old and no older than 65 . We selected from these participants those women who exited cash assistance within three months of our initial observation and remained off the welfare caseload for at least two consecutive months. Our samples included those who returned to welfare within the next calendar year as well as those who stayed off.

\section{Demographic Variables}

The demographic variables were taken from the CARES database and reflect family characteristics as of September 1995, 1997, and 1999. These variable include mother's age, mother’s education level, mother's race, number of children in the household, age of the youngest child in the household, presence of other adults in the household, SSI status of household members, and the county of residence.

The analyses were done at the county level. Counties were grouped as follows: Milwaukee County; other urban counties (Brown, Calumet, Chippewa, Dane, Douglas, Eau Claire, Kenosha, La Crosse, Marathon, Outagamie, Ozaukee, Pierce, Racine, Rock, St. Croix, Sheboygan, Washington, Waukesha, and Winnebago); and rural counties (the other 52 counties in Wisconsin).

\section{Employment and Earnings Variables}

Employment and earnings information came from the Wisconsin Unemployment Insurance database. We have information on quarterly earnings from July 1993 through December 2001 for all the mothers in our sample. These data were used to calculate the presence of earnings and mean and median earnings for each quarter. 
$\underline{\text { Geographic Variables }}$

The percentage of female-headed households by ZIP code was taken from the 1990 census zip code-level database STF3B.

Monthly county-level unemployment rates are from the Wisconsin Department of Workforce Development, Local Area Unemployment Statistics. The reported unemployment rates are for the entire county, except for the following cases:

\section{County \\ Brown \\ Dane \\ Kenosha \\ Marathon \\ Milwaukee \\ Racine \\ Rock \\ Sheboygan}

\author{
Unemployment Rate Reported \\ Green Bay MSA \\ Madison MSA \\ Kenosha PMSA \\ Wausau MSA \\ Milwaukee City \\ Racine PMSA \\ Beloit-Janesville MSA \\ Sheboygan MSA
}

For sample members residing on an Indian reservation, unemployment rates for the following counties were used:

\section{Indian Reservation \\ Red Cliff \\ Stockbridge Munsee \\ Lac du Flambeau \\ Bad River \\ Oneida}

\author{
County Unemployment Rate Used \\ Bayfield \\ Shawano \\ Vilas \\ Ashland \\ Green Bay MSA
}

\section{$\underline{\text { Private Health Insurance Variables }}$}

These variables come from the Wisconsin Family Health Survey for 1998 and 1999. The survey, conducted by telephone on a continuous basis, includes questions abut the health insurance coverage and demographic features of households in Wisconsin. The respondent in each household is the adult with most knowledge of the health status and insurance coverage of all members of the family. The survey results are intended to be representative of Wisconsin household residents. The pooled 1998 and 1999 surveys yielded a sample of 4,894 households and 12,928 residents. 
The survey asks whether each sample member is currently covered (at the time of the survey) by no insurance, private insurance only, Medicaid only, Medicare only, or by four possible combinations. The probit analysis of private insurance coverage utilizes members of the sample who were identified as private insurance only. 


\section{References}

Gruber, Jonathan, and Brigitte C. Madrian. 2001. "Health Insurance, Labor Supply, and Job Mobility: A Critical Review of the Literature.” Ann Arbor, MI.: Economic Research Initiative on the Uninsured Working Paper, November.

Moffitt, Robert, and Barbara Wolfe. 1992. "The Effect of the Medicaid Program on Welfare Participation and Labor Supply,” Review of Economics and Statistics, vol. 74(4): 615-626.

U.S. General Accounting Office. 2001. "Medicaid and SCHIP: States' Enrollment and Payment Policies Can Affect Children's Access to Care.” GAO-01-883. Washington, DC.

Wisconsin Legislative Fiscal Bureau. 2003. “Comparative Summary of Budget Recommendations: Governor and Joint Committee on Finance.” Madison, WI: Legislative Fiscal Bureau.

Wiseman, Michael. 1999. "In the Midst of Reform: Wisconsin in 1997,” Assessing the New Federalism Working Paper 99-03, Urban Institute, June.

Wolfe Barbara, Robert Haveman, Tom Kaplan, and Yoonyoung Cho. 2004. "Extending Health Care Coverage to Low Income Population: The Influence of Wisconsin BadgerCare on Health Care Coverage.” IRP, University of Wisconsin-Madison. 